\title{
NTRK1 Overexpression Positive
}

National Cancer Institute

\section{Source}

National Cancer Institute. NTRK1 Overexpression Positive. NCI Thesaurus. Code

C153060.

An indication that overexpression of NTRK1 has been detected in a sample. 